\title{
«Un bello fantasma formado para lisonjear las almas libres». " La (in) seguridad individual y la expatriación en el Buenos Aires revolucionario**
}

\author{
«A Beauteous Ghost Made for Pleasing the Free Souls». \\ Individual (In) Security and Expatriation \\ in the Buenos Aires of the Revolution
}

\author{
Marcela V. Tejerina \\ ORCID iD: http://orcid.org/0000-0003-2806-5415 \\ Universidad Nacional del Sur, Argentina
}

El trabajo aborda los debates y las ideas en torno a la suspensión de la seguridad individual durante los procesos de expulsión territorial en el Buenos Aires revolucionario. A partir del análisis de sumarios, expedientes, documentación autobiográfica y la prensa periódica, se evalúan la relación entre los derechos y los poderes en los inicios del proceso de construcción republicana y los condicionamientos propios de la cultura jurídico-política tradicional.

Palabras Clave: Buenos Aires; Revolución; Derechos; Poderes; Cultura Jurídico-Política.

This paper addresses debates and thoughts regarding the suspension of individual security at the expulsion proceedings occurred in the Buenos Aires of the Revolution. By means of analyzing summaries, case files, autobiographic documentation and the periodic press, we will evaluate the relation between rights and powers in the beginnings of the republic-building process, and restrictions typical of the traditional legal-political culture.

Keywords: Buenos Aires; Revolution; Rights; Powers; Legal-Political Culture.

Copyright: (C) 2019 CSIC. Este es un artículo de acceso abierto distribuido bajo los términos de la licencia de uso y distribución Creative Commons Reconocimiento 4.0 Internacional (CC BY 4.0).

* Representación al Cabildo de Buenos Aires, 8 de octubre de 1812, reproducida el 22 de octubre de 1812 en Gaceta de Buenos Aires, 1911, 317-320.

** Una primera versión de este trabajo ha sido presentada en el XVIII Congreso AHILA En los márgenes de la historia tradicional. Nuevas miradas de América Latina desde el siglo XXI, Valencia, del 5 al 9 de septiembre de 2017, Simposio 20, «El Atlántico como espacio político (1780-1840)», coordinado por Jean-Philippe Luis, Ivana Frasquet y Claudia Rosas. Asimismo, parte de los contenidos volcados en el mismo han sido parcialmente publicados en Tejerina, 2018, 25-32. 
El 23 de noviembre de 1811, los miembros del primer triunvirato del Río de la Plata firmaban el decreto de seguridad individual. ${ }^{1}$ Fundado en las nociones de juicio previo, legalidad, defensa en juicio e inviolabilidad del domicilio, en su primer artículo establecía que ningún ciudadano podría ser «penado, ni expatriado» sin forma de proceso y sentencia legal. ${ }^{2}$ ¿Por qué en este caso el decreto refería a la expatriación, en forma particularizada, cuando tal alusión no aparecía en ninguna de las fuentes que se le adjudican? ${ }^{3}$

La expatriación — tanto así como el destierro, la deportación, el confinamiento o el extrañamiento-, aludía a una de las formas que asumió la práctica de expulsar del territorio a enemigos y opositores por parte de los sucesivos gobiernos revolucionarios. ${ }^{4}$ De acuerdo al Diccionario de Autoridades, el destierro era entendido como la expulsión o privación de permanecer en su tierra o en otro lugar donde tuviera su domicilio, por tiempo limitado o en forma perpetua. Se hablaba de confinamiento cuando en la decisión del destierro se estipulaba el lugar en el cual este se debía cumplir, de modo tal que refería al acto de destierro acompañado de una asignación y prefijación «del lugar o paraje donde ha de ir, y estar precisamente». En algunas pocas ocasiones, las penas también referían al exilio, vocablo que era lo mismo que destierro, pero de raro uso por aquella época. ${ }^{5} \mathrm{La}$ expatriación, por su parte, se convertiría en una de las formas de expulsión territorial más utilizada por aquellos tiempos y uno de los castigos más extremos, destinado a aquellos considerados responsables de los peores delitos. ${ }^{6}$ En el uso de los contemporáneos, la expatriación solía ser asimilada

1 El decreto llevaba la firma de los triunviros Feliciano Antonio Chiclana, Miguel de Sarratea y Juan José Paso, junto con la del secretario Bernardino Rivadavia. «Decreto de Seguridad Individual», en Caillet-Bois, 1956, 29-30. El primer triunvirato gobernó en el Río de la Plata entre el 23 de septiembre de 1811 y el 8 de octubre de 1812

2 «Decreto de Seguridad Individual», en Caillet-Bois, 1956, 29.

3 Nos referimos a la «Declaración de Derechos del Hombre y del Ciudadano» de 1789 y al «Bill of Rights» inglés. Ver Candioti, 2015, 59-76 y 2017, 44-45. Más tarde, el término «expatriado» se suplantó por «confinado». Ver el «Estatuto Provisional de 1815», en Ravignani, 1939b, 638-650.

4 Para un análisis detallado de las prácticas de expulsión territorial a lo largo de la década revolucionaria en Buenos Aires, ver Tejerina, 2018.

5 Real Academia Española (en adelante RAE), 1726-1739. Para mayores precisiones, ver Tejerina, 2018, 31-32.

6 A pesar de la difusión del término «expatriación» en los documentos de la época revolucionaria, resulta interesante destacar que, según lo que hemos podido verificar hasta la fecha, parece haber comenzado a utilizarse solo después de la revolución. Por otro lado, recién aparecerá en el Diccionario de la Lengua Castellana de 1843, en donde se consigna que expatriarse significaba «Separarse alguno voluntariamente de su patria por mejorar de fortuna o por evitar algún riesgo». RAE, 1843. Un poco más adelante, este vocablo apareció también bajo la acepción de «Echar a alguno de su patria, extrañarle de su país o nación». Salvá, 1846. 
en ciertos casos al extrañamiento. ${ }^{7}$ Dependiendo de la referencia a partir de la cual se planteaba, podemos saber qué dimensión territorial se asignaba a la patria, noción que podría estar remitiendo a la ciudad, pero también a las Provincias Unidas. ${ }^{8}$ De todos modos, la expulsión de la patria, por tanto, la expatriación, en función del espacio territorial al que remitiera, conllevaba la pérdida de tal condición de sujeto social. ${ }^{9}$

Así concebido, el castigo remitía a la doctrina dominante del arbitrio judicial, en tanto equiparaba a la deportación con la muerte civil, pena máxima a la que podía apelar el juez. ${ }^{10} \mathrm{El}$ espacio habitado por la comunidad era en el Antiguo Régimen el que configuraba en forma política y jurídica a los individuos; el territorio mediatizaba los vínculos políticos. Esta territorialidad del poder, explica Hespanha, era propia de las sociedades tradicionales, arraigadas en los fundamentos de la antigua comunidad doméstica: «la equiparación jurídica entre poder y territorio, entre jurisdicción y territorio, se convertiría en sí misma una técnica de control social». ${ }^{11}$ En este escenario, la expulsión del territorio constituyó una forma de exclusión jurídica que se mantuvo a lo largo de los siglos, aún con las transformaciones propias de las penas entre la monarquía corporativa de los siglos XVI y XVII y la monarquía estatalista o administrativa del siglo XVIII. ${ }^{12}$

7 Según el Diccionario de Autoridades, bajo la acepción de «extrañar de los Reinos a uno» se hablaba de extrañamiento cuando el individuo era obligado a salir fuera del reino sin poder permanecer en ningún lugar del mismo. RAE, 1726-1739.

8 Para la época del decreto de seguridad individual convivía el principio de patria, como referencia concreta al lugar de nacimiento, junto con una noción con contenido espacial menos definido y uno social más amplio, con directa alusión sentimental. Más adelante, sobre las décadas del 1830 o 1840, se colocó la noción de patria como un producto de la Revolución. La patria nace de la unión voluntaria de todos los ciudadanos con el fin de fundar la asociación política. Di Meglio, 2008, 115-130.

9 «¿Dónde se ha visto, amigo mío, insultar de este modo los derechos del hombre social, la ilustración del presente siglo, y la buena fe de los americanos del Sur, haciendo asesinar un ciudadano (el extrañamiento perpetuo es muerte civil) y publicando después de su muerte su sentencia [...]?». Segunda carta apologética de Manuel Dorrego, Baltimore, 13 de junio de 1817, en Del Carril, 1986, 186. Para Saavedra, su expatriación se parecía a una proscripción perpetua, fruto del deseo de venganza: «Con este informe la Asamblea, expidió el horrendo decreto de mi proscripción perpetua de estas provincias, digo proscripción, porque en realidad tuvo algo de lo que importa aquella pena. Solo faltó para que fuese propiamente tal, la facultad a todos para que me quitase la vida el que quisiese y la confiscación de mis bienes. Cornelio Saavedra, «Memoria Autógrafa» (Buenos Aires, $1 .^{\circ}$ de enero de 1829), en Senado de la Nación, 1960a, 1067.

10 Hespanha, 1993, 234.

11 Ibidem, 104.

12 Entre los siglos XVI y XVII, el castigo real tuvo más que nada un valor simbólico, sobre todo por la limitada disponibilidad de medios institucionales, logísticos y humanos; ya en el siglo XVIIII adquirió un carácter normativo y práctico, integrado a «una serie de técnica de modulación de los comportamientos sociales», como la propaganda, la educación e, inclusive, la ridiculización. Hespanha, 1993, 210, 239. Sobre la monarquía administrativa, ver Garriga, 2004. 
En tierras hispanoamericanas, los Borbones usaron la expulsión del territorio en forma asidua, en asociación con mecanismos de control y ordenamiento social orientados al disciplinamiento y a la vez como un medio para reforzar los límites más remotos y problemáticos del imperio. ${ }^{13}$ En la medida que permitía la expulsión de aquellos personajes que perturbaban el orden público y desobedecían las leyes, formaba parte de un sistema preventivo utilizado tanto en la península como en los dominios de ultramar. ${ }^{14}$ Caracterizado por el boato barroco de ciertos rituales públicos, tenía un carácter de teatralización que había sabido utilizar para remarcar el poder de los funcionarios reales por sobre el representado en las corporaciones, y con ello, su función ejemplarizante..$^{15}$

A partir del proceso revolucionario, la expulsión territorial en el Río de la Plata fue en principio herramienta de control político de quienes se oponían a la revolución y luego terminó por utilizarse como vía para dirimir los conflictos al interior del propio grupo. ${ }^{16}$ Es que, como ha planteado Hilda Sábato, al mismo tiempo que se iban habilitando diversos recursos y destrezas propias de la vida republicana, la redefinición de las elites políticas, su recambio, ampliación y profesionalización conduciría a un «singular despliegue de dosis variables de violencia», que no dejaría de provocar consternación e incertidumbre aún entre los propios protagonistas. ${ }^{17} \mathrm{Y}$ una de las formas que adoptó esta violencia política fue la del alejamiento compulsivo de todo aquel que no comulgara con las ideas del poder de turno, generalmente aplicada en ausencia del debido proceso. Lo que finalmente interesaba era el alejamiento de los disidentes del escenario del poder. Y con ello vemos la persistencia del ideal de unanimidad que, propio del Antiguo Régimen, rechazaba la disidencia y tendía a la consolidación de una comunidad política unida y sin conflictos en su interior. ${ }^{18}$ A partir de la

13 Roninger y Sznajder, 2007.

14 Ver Agüero, 2008; Aspell, 2008; Navarro García, 2008; Ruiz Astiz, 2010.

15 «En un contexto conflictivo típico del Antiguo Régimen, en donde se entremezclaban cuestiones de ceremonial, protocolo y prelación, el destierro actuó como una medida ejemplarizante, para lo cual generalmente se preparaba un escenario de teatralización efectista que aseguraba la publicidad del acto y el consiguiente escarnio público del implicado». Tejerina y Francisco, 2016, 44.

16 Tejerina, 2018, 14.

17 Sábato, 2010.

18 En tanto propio de la vieja tradición corporativa y de antiguo régimen, el denominado unanimismo ha sido entendido, por un lado, en el marco de una concepción social de comunidad política armoniosa y, por el otro, en relación con la concepción organicista, que sustentaba la representación de la unidad política encarnada por el Soberano, como cabeza de esa unicidad corporal. Ver Guerra, 1994 y Rosanvallon, 2009. Para las implicancias en el terreno político rioplatense del rechazo a la disidencia y a la división del cuerpo político, ver Polastrelli, 2012a y 2012b. 
imagen de la casa, el modelo doméstico de relación política no admitía en el seno de la familia disparidad de intereses ni contradicciones, los asuntos dependían del juicio de oportunidad del padre de familia. ${ }^{19}$

Así como este modelo de ejercicio del poder había constituido la base de la organización política y administrativa de la Corte, ${ }^{20}$ desaparecido el monarca a partir de 1808 y en un contexto revolucionario de creciente conflictividad facciosa, los ilustrados rioplatenses asignarían al decreto de seguridad individual de 1811 un marcado significado político, instrumento legal del orden por encima de las potestades jurisdiccionales y límite de eventuales excesos de los poderes republicanos en formación. ${ }^{21}$ Sin embargo y a pesar de que tal garantía fuera incluida en sucesivos reglamentos y proyectos constitucionales ${ }^{22}$ su vigencia no tendría continuidad en el tiempo. Sucesivas omisiones o suspensiones, de carácter formal como informal, dieron lugar a profundos debates y distintos posicionamientos en torno a la relevancia de los derechos individuales en la estructuración de un proyecto republicano; sus posibilidades, límites y alcances en épocas de conflictos; la responsabilidad de los poderes como garantes de los mismos. En un escenario de gran incertidumbre, importantes transformaciones y desafíos políticos entraban aquí a jugar cuestiones que hacían a la incorporación de nuevas formas de concebir la relación entre poderes y derechos. ¿Cómo se pensaban esas relaciones dentro del contexto político revolucionario?, ¿Cuál era el registro que se tenía de los derechos y el lugar que se les asignaba? ¿Cómo influyeron sobre las prácticas políticas arraigadas? ¿Cuál fue el peso de la cultura jurisdiccional?

19 «Tomando como modelo el gobierno de la casa, así se organizaba el gobierno de la república, cualquiera que fuese su radio: desde la ciudad (una casa grande) hasta el reino, una república de repúblicas cuyo gobierno pertenecía al rey.» Garriga, 2012, 36-37. Para la relación entre el gobierno de la casa y el gobierno de la república en Hispanoamérica ver Zamora, 2017.

20 Hespanha, 1993, 184-187.

21 «Esta cultura [jurisdiccional] concebía y representaba todo acto de poder como la declaración de un orden asumido como existente que se trataba de garantizar y del cual dimanaba su fuerza de obligar. De ahí que, por exagerado que pueda sonarnos hoy, en línea de principio nadie pudiera ser obligado a hacer o soportar algo contra su voluntad si previamente no tenía la posibilidad de defender su derecho judicialmente, con la inevitable y - a los efectos institucionales que aquí importan- decisiva consecuencia de que fuera inconcebible un poder de mando sin jurisdicción (un poder administrativo, en suma), haciendo de los magistrados un elemento decisivo para la gestión de los asuntos comunes en que consiste el gobierno, cualquiera sea el ámbito corporativo y/o territorial considerado. Aunque distinguibles, en estas condiciones la justicia y el gobierno no eran separables, ni en consecuencia podían servir para la estructuración del aparato institucional.» Garriga, 2012, 35.

22 Nos referimos al «Estatuto Provisional» de 1815 redactado por la Junta de Observación; el «Reglamento Provisorio» de 1817 redactado por el Congreso General Constituyente y los proyectos constitucionales de 1819 y 1820 . Ver Candioti, 2015 y 2017. 
Presumiéndose universales, afirma Bartolomé Clavero, no hay historiografía en rigor de los derechos, «como si hubieran nacido y crecieran por encima de culturas y sociedades, de avatares y circunstancias, fuera así en suma del tiempo verdaderamente humano». ${ }^{23}$

En el caso hispanoamericano y en el marco de la convergencia de la nueva historia política y una historia del derecho también renovada, en los últimos años la cuestión de los derechos ha comenzado a cobrar importancia. ${ }^{24} \mathrm{Y}$ esto, en por lo menos dos sentidos. Por un lado, el tema de los derechos del hombre y del ciudadano comenzó a analizarse en relación a las transformaciones de la cultura jurídica y la conformación de los sistemas judiciales. ${ }^{25}$ Así, por ejemplo, frente a la pregunta sobre la manera en que el reconocimiento formal de estos derechos fue incorporándose a la cultura jurídica del Río de la Plata posrevolucionario, Magdalena Candioti optó por rastrear la noción de seguridad individual en el ámbito propiamente de la justicia, a través de un conjunto de expedientes civiles y criminales pertenecientes a los tribunales porteños, entre los años 1810 y $1830 .{ }^{26}$ En la medida en que el «lenguaje de los derechos» fue emergiendo, circulando y manifestándose en los tribunales, afirma la autora, se fueron incorporando «nuevas formas de imaginar lo justo, exigirlo y validarlo institucionalmente». La idea de «seguridad individual» fue un intersticio por el que la idea de derechos individuales y derecho como ley se fue colando y, de ese modo, contribuyó a crear las condiciones que harían efectiva la ley que pretendía garantizarlos. ${ }^{27}$ En forma paralela a esta línea de trabajo y en la medida que fueron surgiendo nuevas preguntas en torno a las revoluciones hispanoamericanas, la problemática de los derechos se ha comenzado a analizar en relación a los procesos de construcción republicana y su incorporación al trabajo constitucional. ${ }^{28} \mathrm{La}$ importancia de estudiar el tema, señala Clement Thibaud, radica en que ellos están en la base de uno de los problemas básicos de la existencia democrática: «la tensión —e incluso contradicciónentre el poder del soberano popular y la protección de cada uno de los miembros de la comunidad contra el leviatán colectivo». ${ }^{29}$

23 Clavero, 2007, 287.

24 Para un estado de la cuestión sobre la confluencia entre la historia del derecho y la historia política ver Barriera y Tío Vallejo, 2012.

25 Ver Palacio y Candioti, 2007.

26 Candioti, 2015 y 2017.

27 Candioti, 2015, 76.

28 Ver Thibaud, 2015. Este autor aborda el proceso de incorporación de los derechos del hombre en el primer constitucionalismo del mundo hispánico, con especial atención a Nueva Granada.

29 Ibidem, 151 
La preocupación por estos derechos era común a todos los revolucionarios hispanoamericanos, afirma Thibaud, aun cuando tal inclusión no hubiera estado presente en la Constitución de Cádiz de $1812 .{ }^{30}$ Las claves que guiaron esta decisión de las Cortes, observa Clavero, se deben buscar en los fundamentos del constitucionalismo jurisdiccional:

Las Cortes Generales y Extraordinarias no han comenzado asumiendo principios que pudieran legitimar para una iniciativa constitucional más franca, aquellos que solo podían ser los derechos y sus garantías, unas libertades y sus requerimientos. A partir de un pronunciamiento de este género, podría haberse generado una acción constituyente más abierta. No fue así como ya sabemos en el caso. El 24 de septiembre de 1810, pese a contarse con ejemplos notorios, la primera determinación de las Cortes no ha sido una declaración de derechos, sino otra de otro objeto, una declaración de poderes. Tras atribuirse de hecho, pero sin identificarlo, un poder que resulta constituyente, han hecho acto seguido distinción entre poderes, el legislativo, el executivo y el judiciario, para la respectiva asignación entre Cortes, Regencia y Tribunales. Esta declaración, la de poderes, no se mantendría por la Constitución en dichos términos, sino en otros de potestades bajo supuestos comunes jurisdiccionales, mientras que la otra, la de derechos, no comparecerá como tal en el texto constitucional, bien que los derechos se registrarán entre los principios del jurisdiccionalismo constitucional vinculante de potestades. En lo que ahora nos importa, no encontraremos los derechos como título de legitimación constituyente. ${ }^{31}$

A diferencia de lo que ocurrió en Cádiz, por tanto, en América Hispana la cuestión de las declaraciones pasaría en forma inmediata del ámbito de la reflexión teórica al de la práctica política, acompañando de este modo la construcción de un nuevo orden republicano. No obstante la importancia de estos procesos, señala Thibaud, hasta ahora los historiadores no les habían prestado demasiada atención. Mientras que la historiografía liberal del siglo XIX adhirió a un «esquema intemporal» $\mathrm{y}$ «difusionista», que entendía la adscripción automática del «modelo» francés en territorio americano, el pensamiento conservador justificó tal «ocultación» por entender que esos derechos solo habían operado en los procesos revolucionarios de modo abstracto e imaginario, en abierto contraste con realidades sociales heredadas de la colonia. ${ }^{32}$

30 Ibidem, 154-155. Como plantea Carmen Serván, respecto de las libertades individuales en orden a la Constitución de 1812: «No hay un iusnaturalismo fundante en Cádiz, como lo hubo en otros textos revolucionarios, ni son los derechos premisas previas.» Serván, 2011, 211. Para un análisis del constitucionalismo español ver Garriga y Lorente, 2007; Martínez Pérez, 1999; Portillo Valdez, 2000. Un estado de la cuestión en relación con América Hispana en Annino y Ternavasio, 2012. Específicamente para México, ver Garriga, 2012.

31 Clavero, 2002, 98.

32 Thibaud, 2015, 150-151. 
Desde la perspectiva de la nueva historia política, sin embargo, y tal como señala Chiaramonte, pensar la relación entre las ideas innovadoras de fuentes europeas y su recepción en Hispanoamérica como un choque entre tradición e innovación o un ejemplo de «resistencia al cambio», es desconocer la permanencia de ciertas creencias subyacentes, que son finalmente las que orientan las respuestas de los hombres. Para eludir esta aparente contradicción, observa el autor, es necesario recurrir a una «historia intelectual bifronte», que ponga atención no solo en el registro del conocimiento que los actores políticos poseían del pensamiento moderno, «sino también en el mucho más difícil rastreo de las creencias que guiaban la conducta habitual en una sociedad y que solían entrar en colisión con las nuevas ideas». ${ }^{33}$

Bajo estos presupuestos, a lo largo del trabajo nos centraremos en el rastreo de los aspectos de la cultura jurídica y política propias de quienes participaron en los debates sobre la suspensión de la seguridad individual en los procesos de expulsión territorial en el Río de la Plata, a lo largo de la década revolucionaria. Recurrimos para ello y en forma preferencial, al extenso acervo de material fontanal édito que refiere a los conocimientos, actitudes y valores de la dirigencia revolucionaria respecto de los procesos aludidos, fundamentalmente sumarios, expedientes y documentación autobiográfica, pero también apelaremos a la prensa periódica y a la correspondencia de particulares. Realizamos una relectura de estas fuentes orientada a la detección de aquellos indicios que nos permitan contribuir a elucidar, si cabe, el modo en que la cultura de los participantes pudo actuar o condicionar las eventuales innovaciones ancladas en la revolución. ${ }^{34}$ Consideramos que, a través del análisis de las discusiones, los argumentos y las ideas de la dirigencia revolucionaria en torno a la suspensión de la seguridad individual es posible evaluar la influencia de los derechos del hombre y del ciudadano en los inicios del proceso de construcción republicana que marcó la vida política rioplatense a lo largo de la década de 1810. Y, desde esta perspectiva, abordar la cuestión de los derechos y los poderes desde un punto de vista histórico y, por tanto, situacional.

33 Chiaramonte, 2016, 191.

34 Si bien las autobiografías a las que hemos recurrido han sido escritas con posterioridad a los hechos, consideramos que constituyen fuentes de información detallada que, si bien remite a las experiencias subjetivas de los autores, luego pueden resultar confrontadas con otras contemporáneas a los hechos referenciados. 


\section{El decreto de seguridad individual de 1811: una lectura política}

En la tarde del domingo porteño del 1 de diciembre de 1811 se juraba en forma pública el Estatuto Provisional del 22 de noviembre, acompañado por el decreto de libertad de imprenta y el de seguridad individual. Dos días después de este acto, la noticia salía publicada en la Gaceta de Buenos Aires, órgano difusor de los actos de gobierno. Se destacaba «la alegría» y «el gozo» de todos por la celebración pública de «un estatuto justo que contribuye a la fortuna y seguridad de todos».$^{35} \mathrm{~A}$ su jura por parte del Superior Gobierno Provisional de las Provincias Unidas del Río de la Plata, le siguió la del Excelentísimo Cabildo, por sí y por el pueblo de la capital, comprometiéndose asimismo a hacer cumplir inviolablemente los decretos que lo integraban. Previamente, el estatuto y los decretos que lo acompañaban se habían leído en voz alta y ante todos los cuerpos civiles, eclesiásticos y militares, «colocados sin presidencia ni etiqueta, acompañando al gobierno». En el acto también se habían hecho presentes gran parte de los habitantes de la ciudad, participando de una instancia de gran trascendencia, en que se habían fijado «las primeras bases de los derechos sagrados del hombre»:

las almas sensibles desfallecían con la novedad de una impresión tan dulce, a que jamás estaban acostumbrados; no creían el acto que presenciaban. ¡Qué diferencia (decían) de jurar obedecer su ignominia, a la de conservar la dignidad de hombre? ? $^{36}$

Pocas semanas antes de este acto público, el triunvirato había disuelto la Junta Conservadora (7 de noviembre de 1811) y derogado el reglamento de división de poderes que esta había sancionado menos de un mes atrás (22 de octubre de 1811). ${ }^{37}$ La Junta Conservadora de los derechos de Fernando Séptimo era el nombre que desde septiembre de 1811 había tomado

35 Noticias sobre la jura del Estatuto Provisional del 22 de noviembre de 1811, publicadas el 3 de diciembre de 1811 en Gaceta de Buenos Aires, 1911, 35. La Gaceta de Buenos Aires se editó entre junio de 1810 y 1821 y constituyó el periódico oficial de los gobiernos revolucionarios, bajo la redacción de diferentes responsables, entre ellos, Mariano Moreno, Gregorio Funes, Pedro Agrelo, Vicente Pazos Silva (Kanki), Bernardo de Monteagudo y Manuel García. Durante el gobierno del Primer Triunvirato, en marzo de 1812, y por iniciativa de Rivadavia tomó el nombre de Gaceta Ministerial, retomando en 1815 su nombre original.

36 Ibidem, 36.

37 El primer triunvirato se instituyó el 23 de septiembre de 1811. El reglamento de división de poderes había establecido un poder legislativo a cargo de la Junta —al cual quedaba subordinado el ejecutivo del primer triunvirato-y un poder judicial «independiente» de los otros poderes, que solo debía ajustar su conducta a las leyes. En forma explícita, se disponía además, que el ejecutivo quedaría excluido de cualquier instancia judicial. Ver Ternavasio, 2007, 64-71. 
la otrora Junta Grande ${ }^{38}$ con la creación de un poder ejecutivo a cargo del triunvirato. Y su disolución debe ser interpretada como punto final de la crisis del juntismo, manifestada crudamente con posterioridad a las jornadas del 5 y 6 de abril de 1811 .

Los hechos de abril de 1811 se habían desarrollado en un clima de gran incertidumbre a nivel internacional y un escenario de enfrentamiento entre morenistas y saavedristas al interior del grupo a cargo del gobierno y la guerra. Los morenistas eran seguidores de las ideas de Mariano Moreno, se oponían a la política de la Junta Grande, reuniéndose primero en el café de Marco y luego nucleándose en la Sociedad Patriótica, bajo el liderazgo de Bernardo de Monteagudo. El segundo grupo, considerado más moderado, estaba liderado por Cornelio Saavedra, presidente de la Junta Grande, y el Deán Gregorio Funes, representante por la ciudad de Córdoba. En la noche del 5 de abril y en medio de la lucha por el control de la Junta y del proceso revolucionario, los alcaldes de barrio de la ciudad de Buenos Aires organizaron una movilización popular en apoyo de los saavedristas, con la presencia de los pobladores de los arrabales de la ciudad en la Plaza Mayor, acompañados por fuerzas militares. Las peticiones que hicieron llegar a los miembros de la Junta fueron finalmente concedidas. Entre ellas, la remoción y destierro de los vocales morenistas vinculados a la recientemente creada Sociedad Patriótica y la creación de un Tribunal de la Seguridad Pública, que terminaría por convertirse en un instrumento de la persecución política.

Como consecuencia de la pueblada del 5 y 6 de abril y «contra razón y justicia» — comentaba un testigo de la época - se decidió el destierro de algunos vocales de la Junta, junto con otros militares, eclesiásticos y funcionarios. ${ }^{39}$ Víctimas de la crueldad y tiranía de Saavedra, observaba dicho testigo, el destierro se había decidido aún «sin oírlos»,

con el mayor rigorismo, habiéndoles quitado los despachos de sus títulos y absolutamente sin darles sueldo alguno para su subsistencia; fuerte rigor, que aún a los

38 La llamada Junta Grande había sido creada el 18 de diciembre de 1810 con la incorporación a la primera junta de gobierno de los diputados de las ciudades que habían integrado el Virreinato del Río de la Plata.

39 Según Beruti, se desterraron los vocales de la Junta Miguel Azcuénaga, Juan Larrea, Nicolás Rodríguez Peña e Hipólito Vieytes; de los militares, Domingo French, coronel del regimiento de Infantería de América y Antonio Luis Beruti, teniente coronel del mismo cuerpo; el clérigo presbítero doctor Ramón Vieytes, el notario eclesiástico Gervasio Posadas, el teniente coronel graduado del regimiento de caballería blandengues Felipe Cardoso y el director de la real imprenta Agustín Donado. Beruti, 2001, 164-166. 
condenados a presidios y facinerosos se les pasa ración; y a unos hombres de graduaciones y méritos, libertadores de su patria, los abandonan a la inclemencia, sin sueldo ni ración alguna, por lo que sin duda alguna iban a perecer a rigores de la miseria y desnudez. ${ }^{40}$

Los hechos del 5 y 6 de abril, afirma Di Meglio, no solo habían dado lugar a una nueva función de la plebe urbana porteña, la de zanjar los conflictos internos a la elite, sino que expusieron también con crudeza la creciente fractura dentro del mismo grupo revolucionario que, si bien ya había comenzado a delinearse en torno a las figuras de Saavedra y Moreno, a partir de estos hechos terminaría radicalizando la acción de cada grupo en relación a los contrarios y con el solo fin de desplazarlos. ${ }^{41}$ La expulsión del territorio - antes reservada especialmente para los españoles europeos contrarios a la revolución—, comenzó ahora a utilizarse para la solución de los conflictos intra elite. Fue una de las prácticas políticas más funestas que se generalizaron a partir de los hechos del 5 y 6 de abril, afirmaría Gervasio Posadas en su autobiografía varios años después:

No nos cansemos: seamos ingenuos y confesemos que en aquella jornada se enseñó al pueblo de Buenos Aires y a todos los pueblos que se podían deponer y desterrar cuatro gobernadores que en esta escuela se han fraguado otras varias mudanzas de gobierno por iguales medios u otros más o menos atroces. ${ }^{42}$

La prensa de la época se encargaría de reflejar el impacto que tuvieron entre los contemporáneos las divisiones manifiestas a partir de aquellas jornadas:

Desde entonces el espíritu público se apaga, el sistema desfallece, progresa la discordia, y empiezan a decrecer nuestras glorias: ya no se habla sino de facciones, las magistraturas y los empleos públicos se distribuyen solo a los parciales, y los pueblos observan con escándalo esta mudanza... ${ }^{43}$

40 Ibidem, 176

41 Di Meglio, 2006, 105.

42 Gervasio Antonio Posadas, «Autobiografía» [Buenos Aires, 19 de junio de 1829], en Senado de la Nación, 1960a, 1413. Recordemos que Posadas fue uno de los desterrados a Mendoza por la pueblada del 5 y 6 de abril. Una vez regresado a Buenos Aires continuó actuando en política, integró el segundo triunvirato desde agosto de 1813 y en enero de 1814 asumió el poder ejecutivo en calidad de Director Supremo. Poco más de un año después, disuelta la asamblea y derrocado Carlos María de Alvear, su sobrino y sucesor en el cargo de director, Posadas recibió sentencia de expatriación a «destinos ultramarinos de Europa». Ver «Sentencia de la Comisión Civil de Justicia» (3 de julio de 1815), en Senado de la Nación, 1962b, 12120-12132.

43 «Causa de las causas», publicado el 20 de diciembre de 1811 en Gaceta de Buenos Aires, 1911,62 
Pocos meses después del triunfo de la facción saavedrista, la intervención del Cabildo de Buenos Aires condujo a importantes cambios. Aprovechando la partida de Saavedra al Alto Perú para reorganizar las fuerzas que habían sido derrotadas en la batalla de Desaguadero (20 de julio de 1811), se decidió la disolución del Tribunal de Vigilancia y, fundamentalmente, la creación del primer triunvirato (23 de septiembre de 1811). Una de las primeras medidas de este triunvirato fue la de permitir el regreso de los desterrados y la sanción del decreto de seguridad individual.

La experiencia vivida durante las jornadas del 5 y 6 de abril -observaba un «ciudadano virtuoso»—, constituían el hito a partir del cual la sociedad había comenzado a valorar la importancia de proteger y garantizar los derechos recientemente explicitados:

Los días de abril nos despertaron, y es preciso que aprovechemos las amargas lecciones que ellos nos dieron. Toda violación de los derechos del hombre sea cual fuese el pretexto con que se haga, amenaza al resto de la sociedad: y si los ciudadanos no vigilan continuamente sobre ellos, jamás faltarán motivos a los ambiciosos, y a los intrigantes para repetir escenas como las del mes de abril. ${ }^{44}$

La prensa rioplatense se hacía eco de estas transformaciones, al informar sobre la jura del nuevo estatuto. Al finalizar el acto, la salva de artillería y fusilería junto con «la aclamación universal del pueblo» anunciaba la general complacencia frente a un hecho que marcaba la sensible diferencia entre jurar una autoridad arbitraria a otra que se constituía como la salvaguardia de la seguridad de los derechos del hombre y dejaba atrás el «dolor por los desórdenes pasados»

Nada era más digno de observarse que el regocijo que se veían en los semblantes de todos, decían, este es el primer acto en que se ha respectado y declarado el derecho del hombre, a su sombra renacerá la justicia, la equidad, el sosiego. ${ }^{45}$

Poner fin al «dolor por los desórdenes pasados», sujetar la fuerza a la razón y la arbitrariedad a la ley aparecían en la letra del estatuto como la misión del recientemente instalado primer triunvirato, en orden a tranquilizar el «espíritu público, resentido de la desconfianza de una tiranía interior». ${ }^{46}$ $\mathrm{Y}$ en los fundamentos del estatuto, el decreto de seguridad individual se

4424 de diciembre de 1811 , Ibidem, 66.

45 Ibidem, 36 y 44.

46 «Estatuto Provisional del Gobierno Superior de la Provincias Unidas del Río de la Plata a nombre del Sr. D. Fernando VII», 22 de noviembre de 1811, en Caillet-Bois, 1956, 25-29. 
presentaba como la salvaguarda para el restablecimiento de la confianza pública ${ }^{47}$ De este modo y en forma articulada con las nociones modernas en torno a los límites al poder y el imperio de la ley, las referencias a los «desórdenes pasados», la «tiranía interior» y la «arbitrariedad popular» en el mismo documento nos conducen directamente a la dimensión política del decreto de seguridad individual. De allí en más, los derechos del hombre, y específicamente el tema de la seguridad individual, comenzaron a aparecer en el centro de la labor publicitaria y pedagógica de la prensa periódica al servicio de los objetivos políticos de las facciones de turno. ${ }^{48} \mathrm{Al}$ trasfondo de temor social, siempre presente en lo referente a la presencia de la plebe en las calles, se sumaba la preocupación poco definida que tenía que ver con la posibilidad de desbordes, de motines, de rebelión esclava, que contaba con el cercano antecedente de Haitít ${ }^{49}$ y el más lejano del terror francés, que se había hecho presente en el tribunal de vigilancia. En pleno enfrentamiento al interior de la elite revolucionaria, la garantía de la seguridad individual se presentaba en la prensa periódica como prueba de la moderación y de la justicia del gobierno en manos del primer triunvirato, frente a la ambición y el fanatismo de ciertos grupos contrarios a la unidad de sentimientos que proponía el sistema liberal. ${ }^{50}$ Los derechos del hombre y del ciudadano se constituían, por tanto, en prenda de diferenciación respecto de quienes habían gobernado hasta entonces. Las revoluciones estaban destinadas a regenerar la sociedad y establecer una forma de gobierno capaz de liberarla de la opresión y encaminarla a la felicidad y al bien público. Y esto solo se lograría demostrando «de un modo efectivo, y real la diferencia del estado actual al anterior: promoviendo las artes, la agricultura, el

47 «i la exisrencia ( (sic) civil de los ciudadanos se abandonase á los ataques de la arbitrariedad, la libertad de la imprenta publicada en 26 de octubre del presente año, no sería más que un lazo contra los incautos, y un medio indirecto para consolidar las bases del despotismo. Todo ciudadano tiene un derecho sagrado á la protección de su vida, de su honor, de su libertad y de sus propiedades. La posesión de este derecho, centro de la libertad civil, y principio de todas las instituciones sociales, es lo que se llama seguridad individual. Una vez que se haya violado esta posesión, ya no hay seguridad, se adormecen los sentimientos nobles del hombre libre, y sucede la quietud funesta del egoísmo.» «Decreto de seguridad individual», en Caillet-Bois, 1956, 30.

48 Ver, a modo de ejemplo, los artículos publicados los días 29 de noviembre de 1811, 24 de diciembre de 1811, 27 de diciembre de 1811, 31 de diciembre de 1811 y 28 de febrero de 1812 en la Gaceta de Buenos Aires, 1911, 30, 31, 57, 66, 72, 73, 74 у 101.

49 Di Meglio, 2006, 107.

50 Ver, a modo de ejemplo, el «Manifiesto del Gobierno publicado junto con la sentencia elaborada a instancias del motín de las "trenzas"», publicado el 13 de diciembre de 1811, y la «Relación de los trabajos del gobierno en los seis meses que han corrido desde su instalación», publicado el 17 de abril de 1812, en la Gaceta de Buenos Aires, 1911, 58 y 159-160. 
comercio, la depuración de la policía y asegurando la libertad, la seguridad y la propiedad del ciudadano»; en el devenir revolucionario hasta el actual gobierno, sin embargo, los derechos de los hombres y de los ciudadanos habían resultado totalmente avasallados: «multitud de hombres fueron confinados, sin ser oídos, hollados los más sagrados derechos». ${ }^{51}$ Con la labor legislativa del primer triunvirato, por tanto, la libertad de prensa aseguraría la publicidad y difusión de las ideas, y la declaración formal de la seguridad individual se constituiría en el reaseguro contra los excesos de una plebe cuya presencia y participación aparecía como insoslayable.

\section{Algunas consideraciones de orden jurídico}

Al derogar el reglamento de división de poderes y sancionar el Estatuto Provisional, el gobierno — como así se identificaba el primer triunvirato - reconocía que, si bien dicho estatuto habría tenido que dimanar de la voluntad de los pueblos y no de un poder ejecutivo que se arrogaba facultades legislativas, el apremio de las circunstancias — se afirmabahacía que el triunvirato asumiera tal responsabilidad, decretando una forma «que prescribiendo límites a su poder, y refrenando la arbitrariedad popular, afiance sobre las bases del orden del imperio de las leyes». ${ }^{52}$ La noción de una ley que venía a salvaguardar los derechos del hombre y la publicidad de su jura por parte de las autoridades en tal acto público, aparecían en la letra del redactor de la Gaceta de Buenos Aires como un claro intento de contrastar y dejar atrás viejas nociones y prácticas ancladas en el orden colonial. De este modo se comenzaba a desdibujar la «acusada impronta garantista del derecho» en el Antiguo Régimen, a tal punto que, como advierte Garriga, en la actualidad «podría resultar llamativa o sorprendente desde ciertos tópicos historiográficos acerca de la monarquía absoluta». ${ }^{53} \mathrm{Al}$ respecto resulta ilustrativa la explicación de Agüero:

$51 \quad 17$ de octubre de 1811, Ibidem, 1910, 823-825.

52 «Estatuto Provisional del Gobierno Superior de la Provincias Unidas del Río de la Plata a nombre del Sr. D. Fernando VII», 22 de noviembre de 1811, en Caillet-Bois, 1956, 28. Cabe acotar que, ya antes del estatuto provisional, el triunvirato se había arrogado facultades legislativas con la firma del decreto de libertad de imprenta (26 de octubre de 1811).

53 Garriga observa que el significado del absolutismo es hoy tan confuso que hasta se discute si conviene continuar utilizándolo. A lo sumo, afirma, el término remite a una tendencia al «ejercicio intensivo y extensivo del poder soberano», el cual no obstante debe continuar recurriendo al pacto «como medio de alcanzar el imprescindible consenso con las corporaciones integrantes del espacio político». Garriga, 2004, 17-19. 
Aunque la tradicional imagen 'feroz' del derecho penal de antiguo régimen viene siendo revisada - afirma Agüero - se suele olvidar que muchos principios adjudicados a la irrupción del pensamiento ilustrado ya encontraban su formulación en la tradición romanocanónica [...] la presencia de ciertos enunciados normativos de garantía no es suficiente para señalar innovaciones puesto que, a pesar del usual desconocimiento, muchas de ellas reconocen un largo historial $[\ldots] .{ }^{54}$

A pesar de lo dicho, vale tener en cuenta para nuestro análisis el hecho de que, aun cuando los principios garantistas hundieran sus raíces en el Antiguo Régimen y ciertas nociones estuvieran en parte ya presentes en la constitución tradicional, a partir de la revolución irían asumiendo un nuevo significado. ${ }^{55} \mathrm{~A}$ la luz de las exigencias de un nuevo orden, observa Candioti, ciertos valores y procedimientos tradicionales podían adquirir un nuevo sentido. ${ }^{56}$ Agüero señala muy claramente esta diferencia para el caso de las normas de garantía:

Para el derecho liberal las normas de garantía se ordenan para proteger derechos subjetivos, para evitar que un ciudadano se vea afectado por una decisión arbitraria de un poder del estado. En la cultura jurídica de antiguo régimen, sin embargo, tal subjetividad humana individual dotada de derechos no es operativa. Las normas de garantía se disponen y se leen en sentido puramente objetivo. Imponen una regla objetiva al juez sobre cómo se debe hacer justicia. Se trata de un esquema de garantía de inspiración religiosa que, en todo caso, propende más a salvaguardar la conciencia (el alma) del juez que a proteger unos inimaginables derechos individuales del reo. ${ }^{57}$

El hecho es que en el Antiguo Régimen y, tal como ha explicado ampliamente Garriga, ese esquema de garantías de inspiración religiosa daba cuenta de una concepción del derecho esencialmente antilegalista, sustentada en la labor del jurista como encargado de mantener un orden dado, un orden jurídico asumido como ya existente y que debía ser mantenido. ${ }^{58}$ Esta cultura jurisdiccional y sus dispositivos institucionales seguirán

54 Agüero, 2010.

55 La constitución tradicional de la sociedad forja los límites del poder soberano y remite a «ciertas condiciones políticas y jurídicas forjadas en la baja edad media que perduran en la moderna, caracterizando por igual (y con independencia de cambios diversos y múltiples transformaciones) a la una y a la otra, que desde este punto de vista pueden quedar englobadas en un período unitario, el Antiguo Régimen» Garriga, 2004, 13-44.

56 Candioti, 2012, 80 .

57 Agüero, 2010.

58 «Los juristas son así maestros de una técnica especialmente apta para organizar el consenso entre perspectivas diferentes y alcanzar soluciones o adoptar decisiones justificadas: que vencen o se imponen porque convencen en el marco de una cultura compartida (y no porque sean expresión de una certeza jurídica previamente definida: entiéndase, legalmente preceptuada)». Garriga, 2004, 15 
prevaleciendo aún frente al avance de la dinámica estatal propia de la monarquía administrativa en el siglo XVIII. ${ }^{59}$ De aquí se desprende que, aún a principios del siglo XIX, la justicia de «jueces» y no de «leyes» ${ }^{60}$ propia de la cultura jurisdiccional recibiera importantes críticas en el ámbito de la justicia rioplatense:

Este ha sido y será hasta que lleguen los días de una saludable reforma, un mal que degrada y envilece la justicia en los tribunales de Indias — se señalaba hacia 1809-. Los virreyes y ministros tienen en sus manos la vida y la muerte. ${ }^{61}$

Estas eran palabras de los procuradores de Juan Martín de Alzaga en el memorial elevado al virrey para su defensa, luego de la frustrada asonada del 1 de enero de 1809 que el comerciante español había liderado para establecer una junta de gobierno:

porque a pesar del alto respecto debido a las personas de los señores virreyes, mucho más a tan larga distancia del solio y de la majestad, la ley que no ha desnudado al hombre de los vicios y pasiones ingénitas por la accidentada investidura de la dignidad y su noble carácter, lo dejó al error sujeto; y por lo mismo dejó al vasallo expuesto al furor, pero con el consuelo de que en los códigos estaban los antídotos. ${ }^{62}$

Frente al arbitrio judicial, los códigos, utilizados por la monarquía estatalista o administrativa como instrumentos de difusión del mensaje legislativo, excediendo de este modo la potestad declarativa del derecho de los magistrados. ${ }^{63}$

Con la revolución, por su parte, el decreto de seguridad individual de 1811 contrapondría la noción de ley positiva, reconociendo por primera vez en forma legal las garantías procesales y penales. De nada servirían las buenas intenciones de los magistrados, señalaba la prensa porteña, si no sujetaban su conducta a una regla que, prescribiendo la forma de gobierno, afianzara la libertad, la seguridad y la propiedad de los ciudadanos. Si ello

59 La monarquía administrativa se orientaba al «ejercicio del poder sin atenerse a los requerimientos procesales de la iurisdictio, que desencadenó en el último tramo del siglo XVIII toda una dinámica estatal» Ibidem, 20.

60 Ver Lorente Sariñena, 2007.

61 Senado de la Nación, 1962a, 10518.

62 Ibidem, 10516.

63 «La ley misma se convierte ahora en un instrumento de propaganda [...] Las nuevas leyes —y las nuevas leyes por excelencia: los códigos_ dejan de ser instrucciones dirigidas a jueces técnicos sobre el orden requerido en un juicio (Gerichtsordnungen) y se convierten en textos para los ciudadanos: escritos en un lenguaje que resulte a estos accesible, se organizan de modo que puedan ser memorizados y comprendidos con facilidad.» Hespanha, 1993, 240. 
no se lograba, «estos serían siempre vejados por la arbitrariedad, oprimidos por el despotismo». ${ }^{64}$ Asomaba entonces un concepto moderno y republicano de la ley que, bajo los principios de legalidad e igualdad, redujera los márgenes de discrecionalidad de los magistrados.

\section{La seguridad individual en debate}

En la medida en que a lo largo de la década revolucionaria la expulsión territorial por razones políticas se fue afianzando, la cuestión de la seguridad individual en torno de estos procesos se convirtió en uno de los temas centrales de discusión y debate, no solo en el ámbito de la prensa periódica sino también en el ámbito judicial. Nos referiremos en particular a cuatro momentos durante los cuales el tema de las garantías aparece en relación a la constitución de los poderes republicanos: primero en el marco de la radicalización de las expulsiones de peninsulares por parte del primer triunvirato; luego, a partir de la suspensión de la seguridad individual durante la Asamblea del Año XIII; en tercera instancia, a lo largo de los juicios a los poderes ejecutivo y legislativo durante 1815 y, por último, a raíz de las expatriaciones de opositores ordenadas por el Director Supremo don Juan Martín de Pueyrredón.

Un breve repaso por estas situaciones nos permite revisar el avance del lenguaje de los derechos entre los protagonistas del proceso revolucionario, en el contexto de la cultura jurisdiccional predominante, y los condicionamientos propios de una realidad política convulsionada y plagada de incertidumbres.

\section{El reclamo de garantías en la representación del 8 de octubre de 1812 al Cabildo de Buenos Aires}

Hacia octubre de 1812, poco menos de un año después de la firma del decreto, el clima político había comenzado a cambiar. Habían sido determinantes el afianzamiento de la Sociedad Patriótica y la organización de la Logia Lautaro, luego del arribo a Buenos Aires de José de San Martín y Carlos María de Alvear. Comenzaba así un proceso de crítica al primer

64 Noticias sobre la jura del Estatuto Provisional, reproducidas el 3 de diciembre de 1811 en Gaceta de Buenos Aires, 1911, 35. 
triunvirato y presión para realizar cambios más profundos, orientados a la declaración de la independencia. En este escenario, la ahora denominada Gaceta Ministerial reproducía la representación elevada al Cabildo por un importante número de ciudadanos, solicitando poner fin al gobierno del primer triunvirato, que ahora se consignaba como despótico y arbitrario. Entre argumentos de distinta índole, la seguridad individual ocupaba un lugar destacado: «La seguridad individual, garantizada de un modo público y solemne, no ha sido más que un bello fantasma formado para lisonjear las almas libres». ${ }^{65}$

El documento elaborado por Bernardo de Monteagudo aludía de forma directa a la serie de ajusticiamientos y destierros de españoles peninsulares, que se había desencadenado hacia mediados de 1812, luego del descubrimiento de la conspiración encabezada por el español Martín de Alzaga contra el gobierno revolucionario y la noticia de la sublevación de los prisioneros peninsulares en Carmen de Patagones bajo el liderazgo de Faustino Ansay. En principio y tras una serie de sumarios, varios de los cabecillas que no fueron ajusticiados terminaron desterrados o expatriados; poco pasó antes que el castigo de la expulsión del territorio recayera sobre todo peninsular que no mostrara adhesión explícita al régimen revolucionario, religiosos incluidos, quedando siempre expuestos al «sistema de delación». ${ }^{66}$

La política de expulsión territorial de los peninsulares reacios a la revolución había constituido desde siempre una de las cuestiones utilizadas por ambos grupos en pugna como bandera para la movilización política en uno u otro sentido. Desde 1810 y en forma paradójica, quienes más habían utilizado esta herramienta política pertenecían al sector políticamente más moderado, el de los saavedristas, afectando a gente con afinidades sociales e incluso vínculos familiares, defendidos por los morenistas, en este caso los del grupo más radical. ${ }^{67}$ Hacia octubre de 1812 y en tanto la cuestión de los peninsulares había recrudecido, el tema de la garantía de la seguridad individual volvería a un lugar central. En el medio del choque de facciones, sería presentado como contrapunto del despotismo y la arbitrariedad que se

65 Representación al Cabildo de Buenos Aires, 8 de octubre de 1812, reproducida el 22 de octubre de 1812 en Gaceta de Buenos Aires, 1911, 317-320. En plena rivalidad con Monteagudo y a instancias de Rivadavia, el primer triunvirato decidió cambiar la denominación del periódico por la de Gaceta Ministerial, constituyéndolo en un órgano dependiente del gobierno. Ver Goldman, 2000, 9-20.

66 Ver Carrera, 2016; García de Flöel, 2000; Pérez, 2012; Polastrelli, 2012b.

67 Di Meglio, 2005, 105-107. 
achacaba al gobierno del primer triunvirato. Finalmente y con el apoyo de la presencia militar en la plaza de la Victoria, la representación al Cabildo del 8 de octubre de 1812 culminó con la disolución del primer triunvirato y el nombramiento de nuevos triunviros, convocados a ejercer el gobierno bajo una serie de condiciones, entre ellas, la de observar el cumplimiento del Estatuto Provisional de 1811, con especial atención al decreto de la libertad de imprenta y el de seguridad individual. ${ }^{68}$ El compromiso del segundo triunvirato con estos principios sería prontamente ratificado:

Si para lisonjear la multitud, ninguna ley es tan propia como la seguridad individual, ella es también la más funesta y acaso peor que un verdadero tiranismo, si se quebranta en un solo ciudadano; porque el ejemplo de la infracción previene el temor, y autoriza el resentimiento de los demás. Esta es una de las causas que ha alegado el pueblo para justificar su conducta, y aunque el gobierno por su institución debe prescindir de la residencia a que están sujetos sus predecesores, conoce sin embargo que el castigo y la deportación de un ciudadano sin preceder un juicio legal es una imperdonable infracción de las más sagradas leyes. Agitados los recelos públicos por esta causa era fácil se aumentasen a la sombra de los peligros [...] Un descontento general se desplegó por todas partes; el funcionario público veía vacilar su destino, el simple particular espera por momentos el decreto de su proscripción: todos temían un trastorno y nadie osaba prevenirlo. ${ }^{69}$

Según el manifiesto del recientemente creado segundo triunvirato, por tanto, la suspensión de las garantías habilitaba de este modo la reacción del «pueblo»y el fin del tirano.

\section{El segundo triunvirato y la Asamblea del año XIII frente a la suspensión de las garantías}

A pesar de manifestarse en contra del avasallamiento de la seguridad individual, poco faltaría para que en nombre de la «seguridad pública e individual de todos los ciudadanos», el segundo triunvirato decidiera el traslado compulsivo de uno de los triunviros depuestos a la ciudad de San Luis. En efecto, según cuenta su hermano, Juan Martín de Pueyrredón sería

68 Acuerdo del Cabildo de Buenos Aires del 8 de octubre de 1812, en Ravignani, 1939a, 727-738.

69 «Manifiesto del Gobierno», Fortaleza de Buenos Aires, 16 de octubre de 1812. Firmado por Juan José Passo, Francisco Belgrano, Dr. Antonio Álvarez Jonte, Juan Manuel Luca, secretario interino, reproducido el 22 de octubre de 1812 en Gaceta de Buenos Aires, 1911, 313-316. 
conducido a la ciudad puntana por razones preventivas, «en el seguro concepto, de que esta disposición no es una pena, sino una medida necesaria y consiguiente al imperio de las circunstancias». ${ }^{70}$

Aludiendo al eufemismo con el cual el gobierno pretendía justificar tal arbitraria expulsión del territorio, el propio Pueyrredón reclamaba fuertemente por la injusticia de una medida que había sido decretada por el «mismo protector de la libertad común e individual», sin respetar el justo proceso. ${ }^{71} \mathrm{Y}$ esta no constituiría una medida aislada. A poco de reunida la asamblea que se había convocado con carácter constituyente y el objetivo de declarar la independencia, el segundo triunvirato reclamó la suspensión de las garantías individuales y la asamblea la aprobó por el término de 6 meses (27 de marzo de 1813), al cabo de los cuales la prorrogó por dos meses más, hasta que la asamblea terminó por disolverse. ${ }^{72}$

El hecho es que en la letra del decreto ya estaba prevista la suspensión temporaria de la seguridad individual, «en el remoto y extraordinario caso de comprometerse la tranquilidad pública o la seguridad de la patria». ${ }^{73}$

En ese caso, el gobierno (léase poder ejecutivo) quedaba habilitado para suspender el decreto, informando a la asamblea en forma inmediata y con justificación de los motivos «y quedando responsable en todos tiempos de esta medida». ${ }^{74}$ En la misma línea de la responsabilidad última del ejecutivo en lo tocante a la suspensión de la garantía de seguridad, el estatuto dado al Supremo Poder Ejecutivo en la sesión del sábado 27 de febrero de 1813 de la Asamblea General Constituyente, establecía que «en caso de invasión o inminente peligro de ella, de sublevación, otro atentado grave contra la seguridad del estado», era potestad del poder ejecutivo suspender

70 Decisión del gobierno, reproducida por José Cipriano Pueyrredón, en «Continuación a la contestación a la carta anónima contra don Juan Martín de Pueyrredón», en Senado de la Nación, 1960b, 2170 .

71 «Es bien fatal el imperio de las circunstancias, me sujetan a un destierro sin poderlo llamar pena, según al concepto de V. E., pero pues ellas han puesto al mismo protector de la libertad común e individual en la necesidad de decretarlo contra un hombre de mis servicios, y sin delito justificado». Idem.

72 Habida cuenta de que en «El Redactor de la Asamblea» no consta información precisa de estas medidas, los datos surgen de las declaraciones de los implicados en el marco de las actuaciones de la Comisión Civil de Justicia en 1815. Ver por caso la lectura de los cargos a Tomás Antonio Valle (Buenos Aires, 26 de mayo de 1815), quien además para la fecha de la suspensión se desempeñaba como presidente de la Asamblea. Ver «Proceso por delitos contra la patria y su seguridad», año 1815, en Senado de la Nación, 1962b, 11958-11959.

73 «Decreto de seguridad individual», en Caillet-Bois, 1956, 30.

74 Ibidem, 31. 
el decreto de seguridad individual, «dando cuenta a la Asamblea General Constituyente de la innovación expresada dentro del término de 24 hs.». ${ }^{75}$

Al cabo del año 1813, las derrotas del ejército del norte en las batallas de Vilcapugio (1 de octubre de 1813) y de Ayohuma (14 de noviembre de 1813), la llegada de refuerzos realistas a Montevideo y el recrudecimiento de los enfrentamientos con el artiguismo habían impuesto un cambio en el rumbo revolucionario. De este modo, se pasaría de una etapa de supremacía del poder constituyente y legislativo a otra de subordinación a un poder ejecutivo que terminó por concentrarse en la autoridad unipersonal de un Director Supremo (31 de enero de 1814). ${ }^{76} \mathrm{La}$ idea de fortalecer el poder central, pasando de una autoridad colegiada a otra de carácter unipersonal, encontraba argumentos en la defensa de los derechos individuales; solo un gobierno fuerte puede evitar la influencia de los intereses de un individuo, de una corporación o de una provincia, se afirmaba hacia mediados de 1813:

Entonces es que un Gobierno puede proteger la libertad, y los Ciudadanos estar seguros de la inmunidad de sus derechos. Si esto falta, la libertad es una quimera: el gran resorte de la sociedad ha perdido su potencia, y al menor choque todo se derrumba. ${ }^{77}$

\section{La seguridad individual en los juicios a los poderes legislativo y ejecutivo}

A pesar de estar contenida en la normativa y de remitir a una decisión del ejecutivo que posteriormente sería aprobada por el legislativo, la suspensión de la seguridad individual constituyó uno de los principales cargos que levantó la Comisión Civil de Justicia de 1815, que se organizó para juzgar a los miembros de los poderes ejecutivo y legislativo luego de la disolución de la asamblea y del derrocamiento del director supremo Alvear. La suspensión de la seguridad individual — se planteaba—, se había aprobado sin razones concretas que la justificaran, en contra de las instrucciones de muchos de los representantes y atentando, por consiguiente, contra las libertades civiles de los ciudadanos. ${ }^{78}$

75 «El Redactor de la Asamblea», en Ravignani, 1937, 17.

76 Ternavasio, 2007, 126-157.

77 Publicado el 21 de julio de 1813, en Gaceta de Buenos Aires, 1911, 498.

78 Las instrucciones a los representantes de Buenos Aires, por ejemplo, aludían en forma específica a la seguridad individual y a la obligación de cuidar que en ningún caso se penase o disminuyese la libertad civil de un ciudadano. Ternavasio, 2007, 195-197. 
La realidad es que, a pesar de las formalidades judiciales, en los hechos la actuación de esta comisión de justicia tampoco aseguraría el debido proceso contenido en el decreto de seguridad aludido. La presión para que se actuara con suma celeridad con el fin de evitar tumultos y conflictos terminó por plagar de irregularidades todo el proceso judicial: «Los sumarios se convirtieron, así, en verdaderas acusaciones fiscales quedando implícita la condena en los términos del interrogatorio y no dando lugar a defensa alguna ${ }^{79}$

No es objeto de este trabajo el análisis de la labor de esta Comisión, que ya ha sido ampliamente estudiada. ${ }^{80}$ Solo nos interesa resaltar algunas de las ideas que se expresaron sobre la suspensión de la seguridad individual durante la Asamblea del año XIII. Las razones aducidas por los asambleístas, en la mayor parte de los casos, aparecían bastante difusas, vinculadas al peligro exterior de una invasión realista desde la península, sobre todo luego de la llegada de refuerzos europeos a la Banda Oriental. Si bien en general los declarantes manifestaban cierto descuido o indiferencia sobre los alcances y límites de la suspensión de la seguridad, hubo quienes, como Hipólito Vieytes, que se mostraron totalmente escépticos sobre la posibilidad de garantizar tales derechos en épocas de revolución: «pero que estuvo entonces, está ahora y estará siempre, que en unos tiempos de revolución, y de una revolución tan complicada que ha acarreado hasta la guerra civil, es imposible establecer de ningún modo la seguridad individual» ${ }^{81}$

Monteagudo, por su parte, deslindaba responsabilidades como diputado por cualquier abuso que se hubiera cometido y reconocía que, en tanto el gobierno fundara su pedido, la asamblea no tenía mucho por hacer. ${ }^{82}$ Ponía el acento de este modo en la responsabilidad atribuida a los miembros del poder legislativo, cuando en realidad la suspensión constituía prerrogativa del ejecutivo. Primaba en estos argumentos una cuestión sobre el orden de los poderes, más que una cuestión de derechos.

Fuera de lo hasta ahora expuesto, predominaba la idea de que, siempre y cuando contribuyera al control político de los adversarios, la relevancia

79 Ibidem, 180-181.

80 Ver Polastrelli, 2012a y 2012b; Ternavasio, 2007.

81 Declaración prestada por Hipólito Vieytes en su casa, por encontrarse enfermo, ante el juez Bartolomé Cueto, Buenos Aires, 11 de junio de 1815, en Senado de la Nación, 1962b, 12032. Vieytes había sido secretario de la Asamblea, al cabo de la cual recibió sentencia de expatriación a destinos de ultramar. No pudo cumplir la sentencia por hallarse gravemente enfermo, muriendo en San Fernando el 5 de octubre de 1815 .

82 Declaración del doctor José Bernardo de Monteagudo, Buenos Aires, 3 de junio de 1815, Ibidem, 12020-12027. 
de la suspensión de las garantías quedaba supeditada al uso que se hiciera de la misma ${ }^{83}$ Para quienes formaban parte de los sucesivos gobiernos, la suspensión de las garantías individuales y el destierro o confinamiento sin juicio previo constituían, en ocasiones, medidas de precaución necesarias para prevenir males mayores. Los fundamentos de esta idea fueron extensamente argumentados por el Dr. Antonio Álvarez Jonte, en ocasión de ser interrogado por la comisión de justicia sobre los motivos por los cuales el «gobierno ejecutivo» creado en 1812 había suspendido el derecho a la seguridad individual. El que manda, «si es un verdadero padre de la patria, y no un tirano debe prevenir las ocasiones, y no echar el lazo de ellas para castigar»; el destierro de algunos ciudadanos durante el régimen asambleísta, en cuanto no buscaba castigarlos sino alejarlos del crimen, no ameritaba pena y volvía innecesaria la sustanciación de causa y proceso. ${ }^{84}$ En ese sentido y como alternativa a la pena de muerte, era considerado por los contemporáneos como una forma que, por ser más compasiva, constituía un medio de equidad. ${ }^{85}$ Vemos entonces que, aún por encima de la directa alusión de Álvarez Jonte a la imagen del «padre de la patria», tradicionalmente asignada a la figura del monarca como cabeza de la república, ${ }^{86}$ en los argumentos de estos revolucionarios resultaban claramente manifiestas las nociones propias de la cultura jurisdiccional, que sustentaban la potestad económica de la cabeza del cuerpo para decidir en orden a la necesidad y la conveniencia en función del bien común. ${ }^{87} \mathrm{La}$ equidad de tales decisiones, por otro lado,

83 «Que el que declara hubiese llegado a conocer que la suspensión de seguridad individual había de acarrear otro mal que la de separar a uno u otro hombre a poca distancia de su casa por sospechas de su conducta en los intereses políticos, no habría prestado su sufragio». Continuidad de la confesión de Hipólito Vieytes, Buenos Aires, 12 de junio de 1815, «Proceso por delitos contra la patria y su seguridad [...]», Ibidem, 12032.

84 Confesión del Dr. Álvarez Jonte, Buenos Aires, 1 de junio de 1815. Ibidem, 12009-12010. Con esos argumentos, afirmaría años después Posadas, «se prendió, se deportó, y se llegó a asesinar jurídicamente en nombre de la tranquilidad pública». Gervasio Antonio Posadas, «Autobiografía», en Senado de la Nación, 1960a, 1478.

85 «un medio de equidad, por el que sin cubrir de luto a las familias inocentes, alejó los males, que pudiera ocasionar a la causa de la humanidad la existencia de aquellos hombres, condenando a los primeros autores a existir por siempre distantes de nosotros en los remotos países de ultramar.» La cita corresponde a un papel titulado «Continuación al Nro. 42 del Censor», publicado el 2 de octubre de 1815, refiriéndose a las sentencias de la Comisión Civil de Justica encargada de juzgar a los miembros del régimen asambleísta, Senado de la Nación, 1960c, 6505.

86 Hespanha, 1993, 177-202.

87 «No en vano su ámbito originario y más propio fue el ámbito doméstico (la casa, en principio familiar), informalmente regido por criterios de oportunidad y conveniencia apreciados por el padre como caput familiae, que sirvió siempre como modelo para la gestión de los asuntos comunes en las corporaciones mayores, incluido el reino (que llegará a asimilarse en este contexto a la casa del rey). Como la familia, cada cuerpo tenía su cabeza, que era la que representaba al conjunto identitariamente 
justificaba la corrección casuística de la ley, como fundamento del margen discrecional del poder ${ }^{88}$ Las expulsiones territoriales basadas en estos argumentos, sin embargo, años después serían muy criticadas por algunos de los contemporáneos. Con esas ideas, afirmaba Gervasio Antonio Posadas en sus memorias, «se prendió, se deportó, y se llegó a asesinar jurídicamente en nombre de la tranquilidad pública». ${ }^{89}$ En definitiva, esas medidas habían impedido poner fin a los resentimientos, pues bastaba que una sola familia quedara herida para que jamás se sofocara el «germen de división». ${ }^{90}$

\section{Los poderes y los derechos durante el directorio de Juan Martín de Pueyrredón}

Hacia noviembre de 1816, el Director Supremo Juan Martín de Pueyrredón desconocía una vez más el derecho a la seguridad individual, al tomar la decisión de expatriar sin juicio previo a Manuel Dorrego de Buenos Aires. ${ }^{91}$ En los mismos términos jurisdiccionales evidenciados en instancias anteriores, Pueyrredón consideraba que tal medida era imprescindible para asegurar el orden y de allí su legitimación:

Estoy encargado de salvar el país, de estrechar los vínculos graduales de todas las clases del Estado, y de preservarlo de los horrores de la anarquía; y un objeto tan noble cuando las pasiones se han sublevado, no es fácil alcanzarse por reglas análogas a tiempos tranquilos. ${ }^{92}$

(o sea, fuera cual fuese su método de designación, que dependía en cada caso de la tradición) y en este concepto estaba dotada de la potestad económica necesaria para tutelarlo, es decir, para adoptar las decisiones relativas al bien del común.» Garriga, 2012, 36-37.

88 Hespanha, 1993, 234-236.

89 Gervasio Antonio Posadas, «Autobiografía», en Senado de la Nación, 1960a, 1478.

90 Gervasio Antonio Posadas, «Notas y Apéndices», Buenos Aires, 12 de julio de 1829, Ibidem, 1468. Recordemos que el mismo Posadas había sido responsable de por lo menos un destierro sin juicio previo durante su mandato como Director Supremo (1814): «me expusieron la necesidad que había de tomar una medida política de precaución contra algunos ciudadanos haciéndolos arrestar y salir de la ciudad, no deportados, sino por algún tiempo, entre los cuales debía ser uno el coronel French, mi primo y hermano político; y ya por esta razón, como por ser la primera y única vez que me ponía en la necesidad de firmar un destierro sin figura de juicio, me opuse tenazmente; pero mi voto en aquella reunión legítima era uno solo [...]». Ibidem, 1480.

91 «Auto de expatriación contra la persona de D. Manuel Dorrego expedido por el Director Supremo del Estado, Buenos Aires, noviembre 15 de 1816», publicado el 26 de noviembre de 1816 en la Gaceta de Buenos Aires, 1912, 695-696. Ver Di Meglio, 2014.

92 Oficio del director Pueyrredón al Soberano Congreso, Buenos Aires, 17 de noviembre de 1816, en Del Carril, 1986, 141. 
Un poco después de la decisión de expulsar a Dorrego, en febrero de 1817, Pueyrredón también resolvía expulsar a los coroneles Domingo French, Manuel Pagola y Feliciano Chiclana, al presbítero doctor Paso [Pazos Kanki], al doctor Pedro Agrelo, abogado de la cámara, el doctor Manuel Moreno, oficial mayor de la secretaría de gobierno, y al oficial mayor de la secretaría de gobierno y doctor José Ignacio Castro. ${ }^{93}$ Eran considerados opositores al gobierno del directorio y acusados de urdir una revolución. Estas situaciones daban prueba fehaciente del «carácter inherentemente problemático del intento de conjurar la arbitrariedad del ejercicio del poder por medio de la ley», como afirma Candioti. ${ }^{94}$ Hacia mediados de la década revolucionaria, la suspensión de la seguridad individual y el destierro per $s e$, en definitiva, la ausencia del debido proceso, constituirían medidas a las que el poder ejecutivo recurriría en diferentes circunstancias, si bien no necesariamente contarían con el aval legislativo. En ocasión de informar sobre la expatriación de Manuel Dorrego y solicitar la aprobación de los congresales reunidos en Tucumán, estos resolvían en contrario bajo el argumento incontrastable de que tal medida no había respetado el derecho a la seguridad individual:

pesando el Congreso las consecuencia que resultarían de aprobar como él solicita la sentencia contra el Coronel Dorrego, que conteniendo una pena capital carece de los requisitos imprescindibles que para tales casos prescriben las leyes de la seguridad individual, en que los pueblos justamente interesados manifiestan un celo siempre despierto y temible en medio de su actual vidriosidad. ${ }^{95}$

Y no es que los congresistas reunidos en Tucumán estuvieran en contra de establecer el máximo rigor contra aquellos que fueran reputados como enemigos del Estado y perturbadores del orden y la tranquilidad pública. De hecho, hacía muy poco habían legislado poniendo a la expatriación al mismo nivel que la pena de muerte. ${ }^{96}$ Vemos entonces que, en tanto hasta el momento los poderes en disputa se habían mostrado incapaces de estructurar y mantener un orden que preservase los derechos de quienes se

93 Beruti, 2001, 277.

94 Candioti, 2010, 52.

95 Tucumán, 5 de diciembre de 1816, Acta de la sesión secreta, en Ravignani, 1937, 518.

96 «Los que promovieren la insurrección, o atentaren contra esta autoridad y las demás constituidas o que se constituyeren en los pueblos los que de igual modo promovieren u obrasen la discordia de unos pueblos a otros, los que auxiliaren o dieren cooperación o favor, serán reputados enemigos del Estado, y perturbadores del orden y tranquilidad pública, y castigados con todo el rigor de las penas hasta la de muerte y expatriación, conforme a la gravedad de su crimen, y parte de acción o influjo que tomaren». Congreso de Tucumán, 1 de agosto de 1816, transcripto en Del Carril, 1986, 104. 
veían involucrados en las luchas facciosas, entre los congresistas reunidos en Tucumán a partir de 1816 se iba consolidando un clima de ideas proclive a la defensa de la seguridad individual frente al eventual avasallamiento de los poderes.

El hecho es que, sobre fines de la década revolucionaria, tales principios constituían la base de los reclamos del coronel Dorrego y las sucesivas representaciones ante el gobierno que hizo a través de su mujer. Al pedir por su derecho a la defensa y a un juicio justo, quedaban claros los principios liberales que sustentaban los reclamos. Su expatriación se había realizado «violando los derechos y privilegios imprescriptibles del hombre, y quebrantando violentamente nuestras leyes», denunciaba Dorrego, en abril de 1817, aquellas leyes plasmadas por esa época en el Estatuto Provisional de $1815 .{ }^{97}$ Solo el imperio de la ley podría asegurar la calidad de un gobierno, afirmaba Dorrego en su primera carta apologética:

Es una insensatez conocida, mi amigo, esperar ningún gobierno justo y sólido, por la buena calidad de sus gobernantes, si no formamos la buena calidad del gobierno. He aquí por qué, en todos los países que no han querido ser esclavos, existe una constitución que obliga a sus mandatarios con arreglo a estas, o las otras condiciones, o leyes, y no dejan a su arbitrio solo el hacer la justicia, porque no quiere obrar de otro modo. Es forzoso, pues, que el gobernante no pueda exceder impunemente sus justos límites, ni dejar de presentar la obediencia a la ley, si no se quieren sufrir abusos los más perjudiciales, injusticias las más atroces, calamidades las más terribles, o caer en una esclavitud más o menos dura, según el carácter más o menos inflexible del que mande. ${ }^{98}$

Los reclamos de Dorrego daban cuenta de un evidente avance en el lenguaje de los derechos hacia fines de la década de 1810, sustentado en la idea de que los derechos individuales debían ser garantizados por leyes positivas, que eran las que debían reglar la actuación de los jueces. ${ }^{99}$ No obstante esto, sus palabras también reflejaban las dificultades que aún

97 Primera carta apologética de Dorrego, Baltimore, 16 de abril de 1817, en Del Carril, 1986, 160. Ver también la nota de Angela Baudrix a la Junta de Observación, Buenos Aires, 19 de noviembre de 1816. Ibidem, 143-144. En su sección séptima el Estatuto Provisional de 1815 retomaba lo establecido por el decreto de seguridad individual e incorporaba en forma explícita el principio de legalidad: «El crimen es solo la infracción de la Ley que está en entera observancia y vigor, pues sin este requisito debe reputarse sin fuerza» Sección Séptima, Capítulo 1, Artículo 3. ${ }^{\circ}$, en Ravignani, 1939b, 638-650. 1986,169

98 Primera carta apologética de Dorrego, Baltimore, 16 de abril de 1817, en Del Carril,

99 «lo que caracterizó al lenguaje de los derechos no fue necesariamente la aparición de categorías nuevas sino de nuevos sentidos para viejos vocablos y sobre todo de nuevas articulaciones entre ellos. Las nociones de código, de ley, de derecho, de gobierno de las leyes, de igualdad, de justicia, no se crearon con la revolución pero se rearticularon y se resignificaron con ella». Candioti, 2015, 62. 
persistían para afianzar un régimen republicano que preservara las libertades conquistadas: «a pesar de los repetidos esfuerzos que se han hecho, leyes y reglamentos que se han dado para dividir estos poderes y evitar estas tropelías», afirmaba Dorrego, el gobierno, en definitiva, el poder ejecutivo, se había erigido en poder judicial. ${ }^{100}$

\section{Algunas consideraciones finales}

A poco de iniciada la revolución en Buenos Aires, la afirmación del derecho a la seguridad individual se constituyó en una de las primeras nociones a las que apeló la dirigencia ilustrada en respuesta a la violencia y al desborde social, desatados a partir de las jornadas del 5 y 6 de abril de 1811. La novedad de llevar la expulsión territorial al interior del grupo revolucionario había hecho que los ilustrados porteños buscaran en el decreto de seguridad individual un instrumento para frenar la amenaza de nuevos abusos y arbitrariedades en el marco de las luchas facciosas que estaban en su apogeo. Sin embargo y tal como observaba Dorrego hacia 1817, transcurridos casi seis años desde la afirmación legal del principio de seguridad individual en el Río de la Plata, la instauración de un nuevo orden que preservara los derechos y libertades ciudadanas mediante una adecuada distribución del poder continuaba siendo una aspiración de incierta consecución. Avanzado el proceso independentista, su vigencia dependería de los avatares propios del desafío de construir un nuevo orden republicano. En todo caso, con su testimonio, Dorrego daba cuenta del modo en que la suspensión de las garantías individuales había ido a la par de la creciente subordinación del poder constituyente y legislativo a un poder ejecutivo que terminaría concentrado en una autoridad unipersonal.

Finalmente, en las ideas y debates en torno a la aplicación de las garantías individuales en los procesos de expulsión territorial, los hombres de la independencia mostraron poseer un amplio registro de los principios del republicanismo y de las ideas modernas que propugnaban el respeto de los derechos del hombre y del ciudadano. A pesar de ello, no contaban con experiencia en la disputa abierta por el poder, a la cual quedaron expuestos a partir de la vactio regis. En este contexto, la expulsión territorial del «otro», aquel considerado adversario o enemigo, resultaría una herramienta política

100 Segunda carta apologética de Dorrego, Baltimore, 13 de junio de 1817, en Del Carril, 1986, 186. 
a la que recurrirían no solo con creciente frecuencia sino, sobre todo, en forma arbitraria. Encontrarían para ello los fundamentos en la cultura jurisdiccional propia de la etapa que intentaban dejar atrás.

Recibido el 11 de enero de 2018 Segunda versión el 9 de julio de 2018 Aceptado el 14 de septiembre de 2018

\section{Referencias bibliográficas}

Agüero, Alejandro, «Formas de continuidad del orden jurídico. Algunas reflexiones a partir de la justicia criminal de Córdoba (Argentina), primera mitad del siglo XIX», Nuevo Mundo Mundos Nuevos, Francia, puesto en línea el 23 marzo 2010, URL: http://nuevomundo.revues.org/59352; DOI: 10.4000/ nuevomundo.59352 [Consultado: 17/02/2016].

Agüero, Alejandro, Castigar y perdonar cuando conviene a la República: la justicia penal de Córdoba del Tucumán, siglos XVII y XVIII, Madrid, Centro de Estudios Políticos y Constitucionales, 2008.

Annino, Antonio y Ternavasio, Marcela, El laboratorio constitucional iberoamericano: 1807/1808-1830, Madrid, AHILA-Iberoamericana-Vervuert, 2012.

Aspell, Marcela, «"Esta cárcel solo sirve para los hombres de bien”: la cárcel capitular de Córdoba del Tucumán. Siglo XVIII», Revista Historia del Derecho, Buenos Aires, La Ley, 10, 5, 2008, 439-467. Disponible en: https://www. yumpu.com/es/document/view/14824398/esta-carcel-solo-sirve-para-loshombres-de-bien-la-clacso [Consultado: 06/07/2018].

Barriera, Darío y Tío Vallejo, Gabriela (coord.), «Dossier: Historia Política e Historia del Derecho», PolHis. Boletín Bibliográfico Electrónico del Programa Buenos Aires de Historia Política, 10, Buenos Aires, 2012, 23-110.

Beruti, Juan Manuel, Memorias curiosas, Buenos Aires, Emecé, 2001.

Bunge Campos, Luis María, «El decreto de seguridad individual de 1811», en AAVV, La cultura penal. Homenaje al profesor Edmundo S. Hendler, Buenos Aires, Ediciones del Puerto, 2009, 181-203.

Caillet-Bois, Ricardo, Estatutos, Reglamentos y Constituciones Argentinas (18111898), Buenos Aires, Universidad, 1956.

Candioti, Magdalena, Ley, justicia y revolución en Buenos Aires, 1810-1830. Una historia política, Tesis de Doctorado en Historia, Facultad de Filosofía y Letras de la Universidad de Buenos Aires. Disponible en http://institutos.filo. uba.ar/ravignani/tesis, 2010 [Consultado: 20/11/2015].

Candioti, Magdalena, «Historia Política e Historia del Derecho: aportes y desafíos de su encrucijada en el estudio de las revoluciones hispanoamericanas y de los procesos de organización estatal», PolHis. Boletín Bibliográfico 
Electrónico del Programa Buenos Aires de Historia Política, 10, Buenos Aires, 2012, 74-80.

Candioti, Magdalena, «Cultura jurídica y revolución. El decreto de seguridad individual y la transformación de la cultura de los derechos en Buenos Aires (1810-1830)», Boletín de la Biblioteca del Congreso Nacional, 129, Buenos Aires, 2015, 59-76.

Candioti, Magdalena, «"Una época en la que Ciudadano ve su seguridad individual respetada". La circulación del lenguaje de los derechos en los tribunales de la Buenos Aires posrevolucionaria (1810-1830)», Secuencia, 98, México, 2017, 35-65. Disponible en http://dx.doi.org/10.18234/secuencia.v0i98.1499 [Consultado: 06/07/2018].

Carrera, Julián, «Bajo el signo de la sospecha. Los pulperos españoles en tiempos de revolución. Buenos Aires, 1810-1820», en Tejerina, Marcela V. y Cantera, Carmen (coord.), Combatir al Otro. El Río de la Plata en épocas de antagonismos, Bahía Blanca, EDIUNS, 2016.

Chiaramonte, José Carlos, «Reflexiones sobre mis trabajos», Boletín del Instituto de Historia Argentina y Americana «Dr. Emilio Ravignani», Tercera serie, 45, Buenos Aires, 2016, 179-217.

Clavero Bartolomé, «Voz de Nación Por Constitución, España, 1808-1811», Giornale di Storia Costituzionale, 4, Macerata, Italia, 2002. Disponible en http://works.bepress.com/bartolome_clavero_salvador/45/ [Consultado: $12 / 06 / 2018]$

Clavero, Bartlomé, El Orden de los poderes. Historias Constituyentes de la Trinidad Constitucional, Madrid, Trotta, 2007.

Del Carril, Bonifacio, El destierro de Dorrego, Buenos Aires, Emecé, 1986.

Di Meglio, Gabriel, ;Viva el bajo pueblo!: la plebe urbana de Buenos Aires y la política entre la revolución de Mayo y el rosismo (1810-1829), Buenos Aires, Prometeo, 2006.

Di Meglio, Gabriel, «Patria», en Goldman, Noemí (ed.), Lenguaje y revolución: conceptos políticos clave en el Río de la Plata, 1780-1850, Buenos Aires, Prometeo Libros, 2008, 115-130.

Di Meglio, Gabriel, Manuel Dorrego. Vida y muerte de un líder popular, Buenos Aires, Edhasa, 2014.

Gaceta de Buenos Aires, Buenos Aires, Junta de Historia y Numismática Americana, tomo II, 1910; tomo III, 1911; tomo IV, 1912.

García de Flöel, Maricel, La oposición española a la revolución por la independencia en el Río de la Plata entre 1810 y 1820. Parámetros políticos y jurídicos para la suerte de los españoles europeos, Hamburgo, LIT, 2000.

Garriga, Carlos y Lorente, Marta, Cádiz, 1812. La Constitución jurisdiccional, Madrid, CEPC, 2007.

Garriga, Carlos, «Justicia y política entre Nueva España y México: de gobierno de la justicia a gobierno representativo», Gayol, Víctor (coord.), Formas de 
gobierno en México. Poder político y actores sociales a través del tiempo, vol. I, Entre Nueva España y México, Zamora (Michoacán), El Colegio de Michoacán, 2012, 33-79.

Garriga, Carlos, «Orden jurídico y poder político en el antiguo régimen», ISTOR. Historia y derecho, historia del derecho, 16, México, 2004, 13-44. Disponible en http://www.istor.cide.edu/archivos/num_16/dossier1.pdf [Consultado: 20/06/2018].

Goldman, Noemí, «Libertad de imprenta, opinión pública y debate constitucional en el Río de la Plata (1810-1827)», Prismas, 4, Quilmes, 2000, 9-20.

Guerra, Francisco Xavier, «La metamorfosis de la representación en el siglo XIX», en Couffignal, G. (comp.), Democracias posibles: el desafío latinoamericano, México, FCE, 1994.

Hespanha, António M., La gracia del derecho. Economía de la cultura en la Edad Moderna, Madrid, Centro de Estudios Constitucionales, 1993.

Lorente Sariñena, M. (coord.), De justicia de jueces a justicia de leyes: hacia la España de 1870, Madrid, Consejo General del Poder Judicial, 2007.

Navarro García, Luis, «Destrucción de la oposición política en México por Carlos III», Naveg@mérica. Revista electrónica de la Asociación Española de Americanistas, 1, 1, Murcia, 2008. Disponible en http://www.um.es/ojs/index. php/navegamerica [Consultado: 08/05/2018].

Martínez Pérez, Fernando, Entre confianza y responsabilidad. La justicia del primer constitucionalismo español (1810-1823), Madrid, Centro de Estudios Políticos y Constitucionales, 1999.

Palacio, Juan Manuel y Candioti, Magdalena (comp.), Justicia, política y derechos en América Latina: apuntes para un debate interdisciplinario, Buenos Aires, Prometeo, 2007.

Pérez, Mariana, « $¡$ Viva España y mueran los patricios! La conspiración de Álzaga de 1812», en Alabart, M., Fernández, M. A. y Pérez, M. (comp.), Buenos Aires, una sociedad que se transforma: entre la Colonia y la Revolución de Mayo, Buenos Aires, Prometeo, 2012.

Polastrelli, Irina, «La disidencia política y sus condenas. Los juicios a Martín de Álzaga, 1809-1812», en Tejerina, Marcela V. (comp.), Definir al Otro: el Río de la Plata en tiempos de cambio (1776-1820), Bahía Blanca, EDIUNS, 2012a, 109-137.

Polastrelli, Irina, «Los revolucionarios se juzgan a sí mismos. Los Procesos de Residencia de 1813 y 1815 en el Río de la Plata», ponencia presentada en las VII Jornadas de Historia Política, Tandil, 6-7 de septiembre de 2012b. Disponible en http://historiapolitica.com/datos/biblioteca/viij_polastrelli.pdf [Consultado: 20/05/2018].

Portillo Valdés, José María, Revolución de nación. Orígenes de la cultura constitucional en España, 1780-1812, Madrid, CEPC, Boletín Oficial del Estado, 2000. 
Ravignani, Emilio, Asambleas Constituyentes Argentinas, seguidas de los textos constitucionales, legislativos y pactos interprovinciales que organizaron políticamente la Nación, Instituto de Investigaciones Históricas de la Facultad de Filosofía y Letras, Universidad de Buenos Aires, Buenos Aires, tomo I, 1937; tomo VI, primera parte, 1939a; tomo VI, segunda parte,1939b.

Real Academia Española, Diccionario de Autoridades, Madrid, Imprenta Francisco de Hierro, 1726-1739. Disponible http://www.rae.es/ [Consultado: 25/03/2016].

Real Academia Española, Diccionario de la lengua castellana por la Real Academia Española, novena edición, Madrid, Imprenta de Don Francisco María Fernández, 1843. Disponible http://www.rae.es/ [Consultado: 25/03/2016]

Roniger, Luis y Sznajder, Mario, «Antecedentes coloniales del exilio político y su proyección en el siglo XIX», Estudios interdisciplinarios de América Latina y el Caribe, 18, 2, Facultad de Humanidades Lester y Sally Entin, Escuela de Historia, Instituto de Historia y Cultura de América Latina, Tel Aviv, 2007. Disponible en: http://www1.tau.ac.i1/eial/images/v18n2/roniger-v18n2.pdf [Consultado: 02/03/2016].

Rosanvallon, Pierre, La legitimidad democrática. Imparcialidad, reflexividad, proximidad, Buenos Aires, Manantial, 2009.

Ruiz Astiz, Javier, «El castigo de destierro en la Navarra moderna: el caso de los implicados en desórdenes públicos», Espacio, tiempo y forma. Serie IV. Historia Moderna, 23, Madrid, 2010, 129-151. Disponible en http://e-spacio. uned.es/fez/eserv.php?pid=bibliuned:ETFSerieIV-2010-22-5070\&dsID= Documento.pdf [Consultado: 10/03/2015].

Sábato, Hilda, «El experimento republicano en el Río de la Plata», Revista de Trabajo, 8, Argentina, 2010. Disponible en http://www.trabajo.gob.ar/downloads/estadisticas/2010n08_revistaDeTrabajo.pdf [Consultado: 15/02/2015].

Salvá, Vicente, Nuevo diccionario de la lengua castellana, que comprende la última edición íntegra, muy rectificada y mejorada del publicado por la Academia Española [...], París, Librería de Don Vicente Salvá, 1846. Disponible http://www.rae.es/ [Consultado: 25/03/2016].

Senado de la Nación, Biblioteca de Mayo, Colección de obras y documentos para la Historia Argentina, Buenos Aires, tomo II, 1960a; tomo III, 1960b.; tomo VIII, 1960c; tomo XI, 1961; tomo XII, 1962a; tomo XIII, $1962 \mathrm{~b}$.

Serván, Carmen, «Los derechos en la Constitución de 1812. De un sujeto aparente, la nación, y otro ausente, el individuo», Anuario de Historia del Derecho Español, LXXXI, Madrid, 2011, 211, disponible en https://www.boe.es/pu blicaciones/anuarios_derecho [Consultado: 22/10/2016].

Tejerina, Marcela Viviana y Francisco, Luciana, «El destierro en la etapa virreinal. Una aproximación a partir de conflictos y prácticas políticas de antiguo régimen», en Tejerina, Marcela V y Cantera, Carmen (Coord.), Combatir al Otro. El Río de la Plata en épocas de antagonismos, Bahía Blanca, EDIUNS, 2016. 
Tejerina, Marcela Viviana, «"Dispersos, emigrados y errantes...” La expulsión territorial en la década revolucionaria», Boletín del Instituto de Historia Argentina y Americana «Dr. Emilio Ravignani», 48, Buenos Aires, 2018, 13-47.

Ternavasio, Marcela, Gobernar la revolución. Poderes en disputa en el Río de la Plata, 1810-1816, Buenos Aires, Siglo Veintiuno Editores, 2007.

Thibaud, Clement, «Las declaraciones de los derechos del hombre y del ciudadano en el primer constitucionalismo neogranadino e hispanoamericano», en González Bernaldo de Quirós, Pilar (dir.), Independencias iberoamericanas. Nuevos problemas y aproximaciones, Buenos Aires, Fondo de Cultura Económica de Argentina, 2015, 149-176.

Zamora, Romina, Casa poblada y buen gobierno. Economía católica y servicio personal en San Miguel de Tucumán, siglo XVIII, Buenos Aires, Prometeo, 2017. 